УДК 657

\title{
АУДИТ В СИСТЕМЕ \\ СТРАТЕГИЧЕСКОГО УПРАВЛЕНИЯ ОРГАНИЗАЦИЕЙ
}

\author{
Масалимов Ильдар Риязович \\ менеджер \\ «Урал-Поволжье Сервис», г. Уфа \\ Масалимов Рияз Ниязович \\ научный сотрудник
}

Международная академия наук и высшего образования, г. Лондон

\begin{abstract}
Аннотация: Эффективное управление организацией требует от руководителей стратегического мышления и умения разрабатывать перспективные планы. Необходимо думать и действовать стратегически, регулярно проводя качественный аудит внешней и внутренней среды организации. В статье определяется место стратегического контроля и аудита в системе управления коммерческой организацией. Определено место служб внутреннего аудита и внутреннего контроля в системе корпоративного управления компании.
\end{abstract}

Ключевые слова: Качественный аудит, внутренний аудит, внешний аудит, стратегическое управление (менеджмент), системный подход.

\section{THE AUDIT IN STRATEGIC MANAGEMENT SYSTEM}

Ildar R. Masalimov Riyaz N. Masalimov

\begin{abstract}
The effective management of the organization requires managers to strategic thinking and the ability to develop perspective projects. The priority is the need to think and act strategically and regularly conducts qualitative audit of internal and external environment of the enterprise. The article defines the place of strategic control and audit system of controlled-profit organization. The place of the internal audit and the internal control system of corporate governance in companies during their development.
\end{abstract}

Key words: Qualitative Audit, Internal Audit, External Audit, Management, the System Approach. 
В исследованиях стратегического характера всегда надо придерживаться точных, вернее, строгих методологических установок. Главным методологическим подходом в данной небольшой статье, естественно, системный подход. В исследованиях учёных из Германии [7], Швейцарии и Австрии [8] системный подход тоже занимает первое место, в отличие от многих работ по контролю и аудиту в коммерческих организациях США и некоторых других стран. Надо сказать, что молодые учёные из России также вносят большой вклад в системный анализ данной проблематики [4; 5]. Методологические проблемы системно-ориентированного аудита впервые рассмотрены донецким исследователем И.Н. Дмитренко [2].

Необходимо обратить внимание вот еще на что. Ещё в начале 1990-х, когда у нас, в России, начались исследования по менеджменту, контролю и аудиту в организациях, вышел на свет трехъязычный (французско-английскорусский) словарь по коммерции и финансам [6]. В этом словаре даны дефиниции аудита в коммерческих организациях, в предприятиях, в компаниях. Уже тогда подчёркивалась важность внутреннего аудита, внешнего (независимого) аудита и контроля и т.д. [6, с. 70-71]. Хотя речи о стратегическом аудите тогда не было, но в словаре были понятия стратегического характера, например, quality audit, General Auditor и пр.

Ныне выделяют разные формы аудита. Общепринятым является его деление на внешний и на внутренний. Как отмечал автор статьи на сайте kp.ru, «внешний аудит — это осуществление аудиторской деятельности независимым аудитором или специализированной организацией. Заказчиками могут выступать собственники, акционеры, инвесторы, кредитные учреждения и государственные органы» [9]. Наши молодые авторы определяют внутренний аудит как элемент системы внутреннего контроля на предприятии [4]. Внутренние аудиторские службы существуют, как правило, в компаниях с разветвленной сетью филиалов. Контроль изнутри помогает руководству осуществлять более грамотное управление, правильно оценивать использование активов, анализировать эффективность финансовых вложений и т.д.

В современной экономической практике служба внутреннего аудита широко распространена во многих российских компаниях. Интерес к ней на протяжении последних лет растет в силу многих факторов, например, таких, как необходимость для собственников и менеджеров контролировать процессы на предприятии; потребность совета директоров в независимом источнике информации о состоянии дел в компании. 
Что представляет собой внутренний аудит, для чего он необходим на предприятии? В чём стратегическое значение для организации? Внутренний аудит, согласно международному Институту внутренних аудиторов, деятельность, направленная на предоставление независимых и объективных гарантий, а также консультаций, направленных на совершенствование деятельности организации. В этом, видимо, не только тактическое, но стратегическое значение аудита и внутреннего контроля.

По характеру заказа можно выделить инициативный (добровольный) аудит и обязательный аудит. В первом случае проверка происходит по решению руководства предприятия, учредителей или органов власти, как правило, для объективной оценки финансового состояния предприятия и достоверности отчетности. Обязательный аудит предусмотрен законодательством, проводят его только независимые аудиторские организации. По виду деятельности экономического субъекта выделяют: банковский аудит (касается банков и иных кредитных организаций); страховой аудит (страховые компании); аудит инвестиционных институтов и бирж; общий аудит (организации прочих видов деятельности). По стадии развития выделяют: подтверждающий аудит, подразумевающий всеобъемлющую проверку и подтверждение достоверности финансовой информации; аудит, базирующийся на риске, при котором проверку проводят выборочно, в основном в «критических точках» - там, где риски выше; области с низкими рисками исключаются из проверки, тем самым сокращается затраченное время. системно-ориентированный аудит, основанный на изучении и анализе системы внутреннего контроля предприятия. Внешняя экспертиза проводится с учетом его результатов.

В зависимости от направления проверки выделяют: горизонтальный аудит - касается одного процесса от начала до завершения без отвлечения на сопутствующие операции; вертикальный аудит - затрагивает все взаимосвязанные процессы; если в результате проверки выясняется, что данная операция связана с другой, аудит распространяется и на нее; аудит в прямом направлении - следует за естественным ходом процесса от начала и до конца (выпуск продукции, предоставление услуги и т.д.); проверка охватывает взаимосвязанные и параллельно выполняемые операции, позволяет оценить качество процесса в целом; аудит в обратном направлении - начинается с оценки выполненной работы (момент приемки продукции или завершение оказания услуги) и движется в обратном направлении к началу; такая форма 
контроля позволяет выявить пропущенные операции и расхождения в документации.

Внутренний аудит можно рассматривать как составную часть системы внутреннего контроля компании, призванной выполнять ряд функций [4; 9]. Целесообразность создавать службу внутреннего аудита заключаются в следующем: во, первых, это позволит эффективнее контролировать деятельность автономных подразделений компании; во-вторых, появляется возможность выявления резервов производства и наиболее перспективных направлений развития; и в третьих, способность оказывать консультативные услуги.

Создание службы внутреннего аудита рекомендуется проводить по этапам: - определение вопросов, которые должна будет решать служба внутреннего аудита; - определение функций, которые обеспечат достижение целей, создание на основе этого структурных звеньев службы, выполняющих эти функции; - определение прав, обязанностей и ответственности каждой структурной единицы, должностных инструкций и положений о бюро (группе, секторе) службы внутреннего аудита; - соединение структурных единиц в одно целое - службу внутреннего аудита, разработка и документальное закрепление Положения о службе внутреннего аудита; - интеграция службы внутреннего аудита с другими звеньями структуры управления предприятием; - разработка внутрифирменных стандартов аудита и Кодекса этики [5]. Решение о создании системы внутреннего аудита принимают собственники компании, которое определяется экономической целесообразностью. С ростом размеров компании и усложнением процессов управления роль внутреннего аудита возрастает. Он является частью системы управления, а также контроля собственниками за деятельностью руководства предприятия. Внутренний аудит важен и менеджменту компании для повышения эффективности принятия решений менеджментом. При создании системы внутреннего контроля необходимо определить ее подчиненность комитету по аудиту совета директоров или непосредственно совету директоров компании. В последнем варианте уровень независимости внутренних аудиторов от исполнительного руководства более высокий, что позволяет с большей эффективностью использовать потенциал системы внутреннего аудита. В том случае, если данный вариант не реализуем, необходимо подразделение внутреннего аудита подчинить высшему должностному лицу предприятия [5]. При этом следует обратить внимание на задачи, которые решает система внутреннего аудита. Если первостепенная 
задача направлена на осуществление контрольно-ревизионной деятельности, то нужно выбрать подчинение высшему исполнительному руководству предприятия. Если же внутренний аудит нацелен на помощь совету директоров эффективно выполнять свои обязанности, следует выбрать подчинение службы внутреннего аудита совету директоров. Структура, а также численность службы внутреннего аудита во многом зависит от целей и задач, которые стоят перед внутренним аудитом, а также от зрелости компании и ее географической разветвленности. Но в большинстве случаев структура и численность службы внутреннего аудита определяются только величиной выделенного бюджета.

Однако при создании системы внутреннего аудита могут возникнуть трудности, связанные с недостаточной регламентацией деятельности, ненацеленностью систем планирования на результат, отсутствием обоснованных показателей для оценки эффективности и результативности деятельности, несовершенством или полным отсутствием управленческого учета, позволяющего обеспечивать контроль достижения результатов, отсутствием системы внутреннего контроля, направленной на обеспечение сохранности активов, проверку достоверности информации, формируемой системой бухгалтерского учета, и повышение результативности деятельности, ориентированностью участников на последующий контроль и недостаточностью предварительного и текущего контроля, которые приводят к ограничению возможности выявления на наиболее ранних стадиях возможных нарушений, недостатков и неэффективного использования ресурсов при осуществлении деятельности [5]. Однако каковы бы ни были трудности, их придется преодолевать, так как внутренний аудит является наиболее действенным инструментом выявления возможностей повышения эффективности деятельности, позволяющий получить информацию, необходимую для достижения целей и решения задач, стоящих перед субъектом, наиболее эффективным способом. Следует отметить, что эффективный внутренний аудит способен сократить затраты предприятия на внешний аудит (внешний аудитор может воспользоваться результатами работы внутреннего аудита, это уменьшит объем аудиторских процедур внешнего аудитора), но не может отменить необходимость внешнего аудита для предприятия. Оценить эффективность функционирования службы внутреннего аудита достаточно сложно в силу того, что результат не всегда можно количественно измерить, существует значительный субъективизм оценки заказчиков. Каждое предприятие само определяет критерии эффективности 
деятельности системы внутреннего аудита. К показателям эффективности деятельности внутреннего аудита относятся: выполнение утвержденного плана аудитов; количество выявленных рисков; процент принятых и выполненных аудиторских рекомендаций; экономический эффект от внедрения рекомендаций; количество повторных аудиторских рекомендаций; удовлетворенность клиентов аудита [5]. Например, мониторинг качества внутренних аудитов. Его осуществляют руководитель и менеджеры СВА с целью установления выполнения аудиторских заданий на должном профессиональном уровне; - внутренние оценки (не реже одного раза в год) с целью выявления собственными силами резервы для совершенствования деятельности каждого внутреннего аудитора, всей СВК; внешние оценки (не реже одного раза в 5 лет), позволяющие получить «взгляд со стороны» на качество деятельности внутреннего аудита. Важным моментом является то, что повышение качества внутреннего аудита достигается при выполнении всех вышеперечисленных мероприятий [4, с. 15-18]. Для эффективной деятельности системы внутреннего аудита необходимо придерживаться таких принципов, как принцип ответственности и принцип сбалансированности. Нужно создавать специальные условия, ставящие работника или подразделение организации в невыгодное положение при появлении каких-либо отклонений и побуждающие их к регулированию «узких мест»; - недопущение концентрации прав первичного контроля в руках одного лица. Сосредоточение первичного контроля в одних руках может стать причиной недостоверного учета; требование заинтересованности администрации. Деятельность системы внутреннего аудита не может быть эффективной без честности, заинтересованности и участия должностных лиц управления; требование приемлемости (пригодности) методологии внутреннего контроля. Об этом так четко в свое время говорила Елизавета Конвей, директор департамента элитной недвижимости Colliers International, Санкт-Петербург [3, с. 12].

Таким образом, внутренний аудит - независимая и объективная деятельность консультационного характера, обеспечивающая конкретные результаты, направленные на повышение стоимости и улучшение работы компании. Многие считают, что внутренний аудит определяет сильные и слабые стороны деятельности компании, является источником ее жизненной силы, заключает в себе тот потенциал, который дает возможность компании функционировать и выживать в условиях рынка. Можно было бы также добавить, какие стратегические преимущества представляет научно- 
технический прогресс, особенно цифровизация аудиторной и контрольных служб [1, с. 15]. Но это потребует дальнейшего исследования.

Итак, в заключение, можно сказать, что роль внутреннего аудита сводится к тому, что он позволяет оценить эффективность деятельности менеджмента, способствует совершенствованию системы внутреннего контроля путем разработки рекомендаций по улучшению, является объективным источником информации. Пожалуй, самое главное - аудит нацелен на решение стратегической задачи, чтобы руководство получало надежную информацию. Наличие службы внутреннего аудита повышает доверие заинтересованных сторон, повышает их уверенность в рациональном использовании компанией ресурсов, сохранности активов, оптимизации рисков деятельности, прозрачности компании. Неслучайно, что целая статья (19-я) Ф3 № 402 «О бухгалтерском от 6.12.2011 г. учете» посвящена внутреннему аудиту. Наконец, всё же стратегический аудит - это комплексный контроль, включающий и внешний аудит, и внутренний аудит.

\section{Список литературы}

1. Ведомости. - 2019. - 30 апреля. - № 79.

2. Дмитренко И.Н. Системно-ориентированный аудит: Проблемы методологии и тенденции развития // Международный бухгалтерский учет. 2007. - № 6. - С. 52-62.

3. На Невском. - 2012. - Август. - № 8.

4. Сонин А. Зачем компании внутренний аудит? // Управление компанией. - 2013. - № 1. - С.15-18.

5. Шегурова В. П., Трунтаева Ю. В. Внутренний аудит в системе управления предприятием // Молодой ученый. - 2013. - № 5. - С. 424-427. URL: https://moluch.ru/archive/52/6890/ (дата обращения: 18.05. 2019).

6. Gavrichina K.S., Sazonov M.F., Gavrichina I.N. Dictionnaire commercial et financier. - Moscou: VIKRA, 1993. - 792 p.

7. Pfriem Reinhard. Strategisches Management // URL: https://uol.de/fileadmin/user_upload/c3I...

8. Strategisches Audit im Organisationsmanagementsystem // URL: https://www.mab-edu.com/strategie-audit-inh13/.

9. URL: https://www.kp.ru/guide/vneshnii-i-vnutrennii-audit.html/ (дата обращения: 19.05. 2019). 